\title{
Introduction to the Special Issue:
} The International Symposium on the Sociology of Music Education, and the MayDay Group Action Ideals

\author{
Gareth Dylan Smith \\ New York University, USA \\ Clare Hall \\ Monash University, Australia
}

This special issue of Action, Theory, and Criticism for Music Education (ACT) explores some of the current problematics being tackled through sociology of music education, as well as how the work of this group of scholars intersects with the MayDay action ideals. This collection of papers presented in 2017 at the International Symposium on the Sociology of Music Education (ISSME) London, UK, illustrates the strong connections between the two organizations. A confluence is evident in the groups' agendas to promote meaningful action in the world, in and through music education. This introduction outlines how the contributors' work goes about this through critical research and practice that challenge the status quo in music education.

Keywords: sociology, music education, critical theory, change, practice

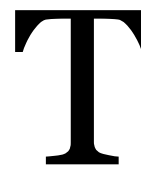

his special issue began with the International Symposium on the Sociology of Music Education (ISSME) in London, UK, in 2017. The conference planning committee approached Vincent Bates, editor of Action, Theory, and Criticism for Music Education (ACT), with a proposal to publish a special issue of the journal, based on papers presented at ISSME. Vincent agreed, and this collection of papers resulted from that collaboration-the fourth such special issue to issue from ISSME. This collection provides a snapshot of ideas that were presented, that indicate the kinds of problematics sociology of music education is tackling, as well as how the work of this group of scholars intersects with the

(C) Gareth Dylan Smith and Clare Hall 2018. The content of this article is the sole responsibility of the author. The ACT Journal and the Mayday Group are not liable for any legal actions that may arise involving the article's content, including, but not limited to, copyright infringement. 
MayDay action ideals. Hildegard Froehlich, a founder of ISSME in 1995, impressed upon attendees in 2017 that we must ensure our scholarly, wellresearched, well-meaning, and plentiful words lead to action. This was not the first time Hildegard, or indeed any member of the ISSME community has felt a need to remind us to act, as well as to write, think, and talk. This is not suggesting that those attending the conference do not act, of course. The presentations and discussions at ISSME demonstrate that many attendees are indeed engaged in research and teaching have demonstrable effects in communities and cities around the world. Nor is it our intention to devalue the 'practice of theorization' that was also in evidence at the Symposium; as sociologists, we all understand and treasure opportunities we have as academics to spend time conceptualizing, problematizing, and understanding the world of and surrounding music education. Hildegard's point was, moreover, that we must not stop at the words. The words must lead into direct action.

The MayDay Group, the professional society with which ACT is affiliated, and with whom ISSME has shared conferences/colloquia in the past, has the "twofold purpose":

- to apply critical theory and critical thinking to the purposes and practices of music education, and

- to affirm the central importance of musical participation in human life and, thus, the value of music in the general education of all people.

This purpose is unpacked and expanded in the MayDay group's "Action for Change" (1997), in which the authors articulate several "ideals for necessary change" (2). Herein the authors assert that:

All music must be seen as intimately tied to social and cultural contexts and conditions. The theory and practice of music education must account for this situatedness of music and music-making. Music educators must have, therefore, a theoretical foundation that unites the actions of producing music with the various contexts of those actions, so that musical meaning appropriately includes all of music's humanizing and concrete functions. $(1997,2-3)$

This statement outlines a rationale of, and a call to action for, a sociology of music education. As such, it is reflected in the papers that follow in this special issue. The authors of "Action for Change" go on to articulate another premise underpinning sociological enquiry in music education. They assert that:

Smith, Gareth Dylan, and Clare Hall. 2018. Introduction to the special issue: The International Symposium on the Sociology of Music Education, and the MayDay Group action ideals. Action, Criticism, and Theory for Music Education 17 (3): 1-11. doi:10.22176/act17.3.1 
A musical culture is a living process, not a set of works or of given practices. It develops out of the special synergy of change and tradition unique to its people and conditions and cannot simply be passed on as a timeless, unchanging set of traditions.

These editors acknowledge the powerful synergy between the MayDay Group and the International Symposium on the Sociology of Music Education. It is one that has been recognized previously, including in previous ACT special issues dedicated to proceedings of ISSME (Dyndahl, Karlsen, and Wright 2014; McClellan 2016).

ISSME is a community of scholarship established through and at a biennial conference. In the absence of any statutory governance, ISSME has a history and a group sense of identity. It is a peer community. That community collectively curated this special issue of ACT. The papers published here were first submitted as abstracts for consideration to be included in the 1oth iteration of ISSME in London, England in June 2017. A scholarly committee of three blind reviewers reviewed the papers along with the chair of the conference who had seen the authors' names. These authors' abstracts were accepted for presentation, developed into conference papers, presented, and discussed at the conference, further developed, and submitted for consideration to be included in this special issue. The guest editors and the editor of ACT selected these papers from eight submitted and they underwent a round of blind peer review, before being further reviewed by the guest editorial team, and then copy-edited and formatted ahead of publication. The guest editors and peer reviewers at all stages of the process selfidentify as sociologists working in music education. In this way, the contents of this special issue reflect and represent the contemporary community in the emerging sub-field of the sociology of music education.

A confluence exists between the key driver of ISSME to work critically in research and practice in order to challenge the status quo in music education, and the MayDay Group's “Action for Change”. To further illustrate this, scholars submitting work to be considered for publication in ACT are asked to ensure that their work speaks to one or more of the May Day Action Ideals, developed in 2012 from the "Action for Change". It is therefore worth dedicating a little space here to considering how the articles in this ISSME special issue meet the aims and call to action of these Action Ideals. What follows is not a comprehensive analysis, but rather a brief summary of the synergy that these editors see between the in-

Smith, Gareth Dylan, and Clare Hall. 2018. Introduction to the special issue: The International Symposium on the Sociology of Music Education, and the MayDay Group action ideals. Action, Criticism, and Theory for Music Education 17 (3): 1-11. doi:10.22176/act17.3.1 
tentions and work of the authors, sociological debates in music education, and the Action Ideals of the MayDay Group. Our intention in what follows is to help enable a reading of the issue's contents, that takes into account the potential of all of these words, for genuine, meaningful action in the world, in, and through music education.

\section{This ISSME Special Issue and the MayDay Group Action Ideals}

The first May Day Action Ideal states:

All music and music learning is culturally situated. Diverse communities generate and sustain diverse musical meanings, values, and individual practices. Thus, music learning works best when we are mindful, reflective, and critically aware of cultural contexts.

The cultural situatedness of music-making and music-learning, and the generation of meaning-making in particular contexts, are explored throughout the papers in this special issue. They are the most vividly portrayed in Danielle Sirek's evocative ethnographic research on Grenadian calypso and soca musicking and music education. Sirek's research emphasizes the power of meanings in music, for groups and individuals in particular times and locations. It explores tensions that arise as socio-musical cultures clash, collide, and coexist, with calypso (primarily the music of an older generation) frequently political in nature, and soca (preferred by younger Grenadians) typically emphasizing corporeal and hedonistic pleasures. Terry Sefton's paper discusses music learning among faculty and students in the contexts of four workshop residencies in different university contexts. Insights emerge regarding learning in the intense, fleeting communities of the workshops, and in the broader context of a Canadian society wherein university education is construed, constructed, and constrained by policies that emphasize an instrumentalist, functional, neoliberal perspective. A shared foundational assumption of the ISSME community is that music educators serve our students and the wider world best when we are (in the words of the first MayDay Action Ideal) "mindful, reflective, and critically aware of cultural contexts"-including those contexts comprising our own actions, beliefs, and identities.

Smith, Gareth Dylan, and Clare Hall. 2018. Introduction to the special issue: The International Symposium on the Sociology of Music Education, and the MayDay Group action ideals. Action, Criticism, and Theory for Music Education 17 (3): 1-11. doi:10.22176/act17.3.1 
The second MayDay Action Ideal states:

Since social, cultural, and political contexts of musical actions are integrally tied to the nature and values of all human activity, a secure theoretical foundation that unites the actions of music with the various contexts and meanings of those actions is essential to music education in both research and practice.

This reminder of the importance of the theoretical foundation to understanding and action in music education, underpins and is embedded in each of the papers in this issue. Sociology compels researcher-educators never to be content merely to describe what we see. We need to understand events, actions, beliefs, and practices, in order to act conscientiously and responsibly within and towards cultures. Towards this end, the articles in this special issue contribute to the necessarily evolving theoretical foundation for music educators and scholars. In her paper, Danielle Sirek develops theoretical understanding based on Tönnies' (1887/2017) constructs of Gemeinschaft and Gesellschaft; Ed McClellan examines music education undergraduates' identity construction through the lens of Wenger's (1998, 2009) construct of communities of practice; Flávia Narita considers Freire's (1970) notion of conscientization in relation to a mixed-mode distance education undergraduate music program at the Open University of Brazil; and Terry Sefton considers informal and non-formal music learning (Green 2001, 2014; Wright 2010) in liminal learning spaces of practice as research.

The third MayDay Action Ideal reads:

As agents of social change who are locally and globally bound, we create, sustain, and contribute to reshaping musics, ways of knowing music, and spaces where musicing takes place. Thus, music educators must always strive to provide equitable, diverse, and inclusive music learning practices.

The writers in and editors of this special issue are each deeply aware of the impact that they have as educators and as writers-knowledge creators and disseminators-and the power that, consciously and unconsciously, we wield over musics, ways of knowing, identity realization, and, through these process, personhood. We hope to be inclusive, diverse, and equitable in our practices. Although ISSME meets biennially in different locations, it is yet to travel outside of the wealthy global north, gathering exclusively in North America (usually the USA) and Europe. This special issue goes some way to redress this bias with four

Smith, Gareth Dylan, and Clare Hall. 2018. Introduction to the special issue: The International Symposium on the Sociology of Music Education, and the MayDay Group action ideals. Action, Criticism, and Theory for Music Education 17 (3): 1-11. doi:10.22176/act17.3.1 
papers that showcase diverse perspectives. Danielle Sirek shares insights from research undertaken in Grenada, described above, and Flávia Narita looks at ways of innovating online teaching to improve Brazilian students' distance learning; she goes on to explore some of the complexities and challenge some of the assumptions we might hold around such supposedly democratizing practices and approaches. Terry Sefton discusses the role of informal pedagogies for promoting inclusive and creative learning spaces. Ed McClellan's essay seeks to help professors understand better the identity realization of students, in order that faculty might be able to enhance the ways they serve students as educators and mentors.

\section{Ideal number four asserts:}

Like all elements of musical culture, contributions made by schools, colleges, and other institutions must be systematically and critically examined in order to evaluate the extent and directions of their influence.

This action ideal is one that is perhaps most aligned with the work of the attendees at ISSME conferences. This careful, deep, introspective focus on scholars' day-to-day work, combined with an energetic concern, regard, and compassion for the effects and impact of that work, are at the heart of the work that we all do. This is at the core of the sociology of music education. With the exception of Danielle Sirek's chapter, each of the papers in this special issue is concerned with critical examination of the cultures and contributions of particular schools or colleges. McClellan's paper makes a significant methodological contribution with his systematic quantitative analyses-rare in music education sociology-to pursue his questions of culture and identity in higher music education. Sirek's paper, by contrast, implicitly challenges individuals, departments, and schools to consider what musics are excluded from their cultures and canons, and, by extension, to examine the roots and characteristics of those cultures.

Ideal number five affirms:

We commit to fostering ongoing engagement with fellow music educators of all traditions, seeking knowledge from disciplines other than music, and collaborating with practitioners of those disciplines.

This special issue does not represent an overtly multidisciplinary approach, such as that for which the fifth action ideal calls. After all, this short collection is

Smith, Gareth Dylan, and Clare Hall. 2018. Introduction to the special issue: The International Symposium on the Sociology of Music Education, and the MayDay Group action ideals. Action, Criticism, and Theory for Music Education 17 (3): 1-11. doi:10.22176/act17.3.1 
bound together by an orientation toward sociologically informed inquiry. However, the articles are somewhat transdisciplinary inasmuch as the contributing authors demonstrate some scholarly boundary-blurring in their work. They combine knowledge from fields beyond music education, with Sefton collaborating with a dancer through arts-based practice, McClellan integrating Vygotskian cultural-historical elements with roots in developmental psychology; Sirek's writing has clear ethnomusicological underpinnings, and Narita's essay gives more than a nod to critical pedagogy. Nonetheless, the papers herein are few, and as such necessarily represent a relatively narrow portion of societies and a commensurately non-diverse range of cultures-although each is about research conducted in a different country; papers herein are about Brazil, Canada, Grenada, and the United States. Sociology invites and requires music education scholars and practitioners to be broad in our views of musical traditions, and to acknowledge how music's meanings are contingent upon conditions and contexts both of production and of reception. Sociology, therefore, seeks not to judge but to understand, and to do so with humility and respect.

Ideal number six reminds us:

We must continually refine and broaden scholarship for music education in terms of inclusivity, relevance, and theoretical and practical interest.

Along with ideals numbers two and four, this sixth action ideal aligns very closely with the individual and collective aims of scholars in the sociology of music education. Refining and broadening scholarship may seem mutually incompatible, since they appear to pull in different directions-one toward more specificity, the other towards less; however, as a community of scholars it is possible to achieve both, as is hopefully demonstrated in part by the papers that follow. The theoretical and practical also can also be construed as opposite to or incompatible with one another, but a recurring theme of ISSME gatherings and this collection is that these require and rely on one another; education, after all, is action. In considering our actions in music education, Juliet Hess articulates the following in regard to inclusivity:

The colonial relations inherent in research involve power relations. As music education researchers, we encounter power dimensions outside of music including power dynamics between identities, between teacher and student, within

Smith, Gareth Dylan, and Clare Hall. 2018. Introduction to the special issue: The International Symposium on the Sociology of Music Education, and the MayDay Group action ideals. Action, Criticism, and Theory for Music Education 17 (3): 1-11. doi:10.22176/act17.3.1 
communities, between communities, within schools, and beyond. We also encounter power dynamics intrinsic to music, music education, and musicking practices. These dimensions include relationships between teacher and student, between identities, and the classed, gendered, raced, ableist, and heterosexist dimensions of music education. Music-specific power relations often relate to issues of representation, access, and salvationist and Eurocentric assumptions of what musics and programmes may be useful for particular populations of students. (Hess 2018, 13)

In our efforts to be inclusive, it is essential for scholars to be cognizant of ways in which, as Hess and others have articulated, we represent, replicate, and reproduce power relations endemic to our work and our field.

\section{Ideal number seven asserts:}

An ongoing reflective effort towards understanding the context of music curriculum and education must serve as a common starting point for nurturing robust communities of music educators and learners. We are committed to engaging a discussion which reframes all musical learning, including what takes place in schools, as a lived and diverse set of practices that encourages practitioners to be critically reflexive towards concepts of music pedagogy and curriculum as well as those practices represented in local, national, and global paradigms in education.

This seventh action ideal reads as an extension of the sixth and all but stands on its own as a mandate for how to do music education research. There is 'no daylight' between this and the stated imperatives of leaders in the sociology of music education. It is, though, worth adding the following consideration on "social reproduction" from Lucy Green, for the impetus it gives towards this reflexive reframing:

Music education is intended to enhance and appraise students' musical abilities, but at the same time there may be something else altogether going on. This proposition can be considered on two levels, one reflecting the experience of the individual student, in all the diversity that implies; and the other concerning the production and reproduction of large-scale social groups and corresponding patterns of advantage and opportunity to which the education system makes such a powerful contribution. (Green 2014, 59)

Green goes on to explain the tremendous opportunity that is offered by music education, arguing that "music education continues to be worthwhile: for although education has reproductive effects ... it also offers us the potential to challenge our understanding and awareness at a deep, symbolic level, through bringing to-

Smith, Gareth Dylan, and Clare Hall. 2018. Introduction to the special issue: The International Symposium on the Sociology of Music Education, and the MayDay Group action ideals. Action, Criticism, and Theory for Music Education 17 (3): 1-11. doi:10.22176/act17.3.1 
gether new and previously disparate meanings and experiences" (63). Green concludes her point by reminding us that such a perspective "carries a caution: against making any assumptions about how music is understood by others" (63).

\section{Ideal number eight states.}

We commit to understanding the wide range of possibilities and the limitations that technology and media offer music and music learning.

A paper that explicitly addresses this ideal in this collection is Flávia Narita's article focusing on exploring the possibilities and limitations of technology in music education, in the context of distance learning at a Brazilian university. This work's consideration of some of the challenges posed by technological determinism makes a significant contribution to debates as the inextricable interweaving of digital technologies with music education represents an area in great need of further sociological inquiry. Issues of how we are who we are, and negotiation of power relations in all domains of society, perhaps require that this community should pay increasing attention to technology.

\section{In Conclusion}

The MayDay Group Action Ideals have helped to frame this special issue by 'taking stock' of ISSME's values, and illuminating synergies in this interdisciplinary sub-field of music education and sociology research. It is pertinent to reflect on how this group of sociologists' work aligns with the MayDay Group's vision and call to action, and-as with any rubric-it is instructive to see where and in what ways one's own work may or may not align with certain provocations and ideas. The collection of papers in this special issue is small, and therefore unrepresentative of the breadth of scholarly interests held by members of the ISSME community. As we look to future ISSME gatherings and to the publications that will continue to emerge from the invigorating discussions ensuing there, we anticipate investigations that embrace interdisciplinarity, cultural diversity, practiceas-research, and myriad multimedia manifestations of music-making in the twenty-first century. In alignment with the overall aims of this journal, we note, in closing that:

Smith, Gareth Dylan, and Clare Hall. 2018. Introduction to the special issue: The International Symposium on the Sociology of Music Education, and the MayDay Group action ideals. Action, Criticism, and Theory for Music Education 17 (3): 1-11. doi:10.22176/act17.3.1 
The distinctiveness of a sociology of music education would lie in the necessity to wed theory with practice as an ongoing imperative for music educators. Always thinking in application to practice, teachers tend not to be satisfied with the articulation and examination of theoretical constructs alone. Instead, they want to know what constructs do for taking actions toward improving learning and teaching processes. (Froehlich and Smith 2017, 10)

We urge you to read, then to act.

\section{About the Authors}

Gareth Dylan Smith is Manager of Program Effectiveness at Little Kids Rock, and Visiting Research Professor at New York University, USA. Gareth's book I Drum, Therefore I Am: Being and Becoming a Drummer - the world's first sociological study of drummers - was published in 2013. His other books include the Routledge Research Companion to Popular Music Education (2017), the Oxford Handbook of Music Making and Leisure (2016), Punk Pedagogies: Music, Culture and Learning (2017), Sociology for Music Teachers: Practical Applications, second edition, with Hildegard Froehlich (2017), and The Music Learning Profiles Project, with Radio Cremata, Joe Pignato, and Bryan Powell (2018).

Clare Hall is Lecturer in Performing Arts at Monash University, Australia and Leader of the Arts-Creativity-Education research group in the Faculty of Education. Her research is in the sociology of the arts, with a focus on music and dance across cultures. Her research explores the intersection of gender, class, ethnicity and age in arts participation, with special attention to Australian Indigenous arts. Clare is author of Masculinity, Class \& Music Education (Palgrave, 2018) and is Vice-Chair of the International Symposium on the Sociology of Music Education. Her education work with pre-service teachers promotes trandisciplinary learning through the integration of the temporal arts and embodied ways of knowing across the curriculum.

\section{References}

Dyndahl, Petter, Karlsen, Sidsel, and Wright, Ruth, eds. 2014. Special issue. Action, Theory, and Criticism for Music Education, 15 (3).

Friere, Paulo. 1970. Pedagogy of the oppressed. Translated by Myra Bergman Ramos. New York, NY: Seabury Press.

Froehlich, Hildegard C., and Gareth D. Smith. 2017. Sociology for music teachers: Practical applications. New York, NY: Routledge.

Smith, Gareth Dylan, and Clare Hall. 2018. Introduction to the special issue: The International Symposium on the Sociology of Music Education, and the MayDay Group action ideals. Action, Criticism, and Theory for Music Education 17 (3): 1-11. doi:10.22176/act17.3.1 
Green, Lucy. 2001. How popular musicians learn: A way ahead for music education. Aldershot: Ashgate.

Green, Lucy. 2014 [2005]. Musical meaning and social reproduction: A case for retrieving autonomy. In Music education as critical theory and practice: Selected essays, edited by Lucy Green, 49-64. Farnham: Ashgate.

Hess, Juliet. 2018. Challenging the empire in empir(e)ical research: The question of speaking in music education. Music Education Research, 1-18. doi:10.1080/14613808.2018.1433152

MayDay Group. 1997. Action for Change in Music Education. http://mayday group.org/wp-content/uploads/2014/o8/ActionForChange1997.pdf

MayDay Group. 2012. Action Ideals. http://www.maydaygroup.org/aboutus/action-for-change-in-music-education/\#.WvuKedMvxE5

McClellan, Edward, ed. 2016. Special issue. Action, Theory, and Criticism for Music Education, 15 (3).

Tönnies, Ferdinand. 1887/2017. Community and society (Gemeinschaft und Gesellschaft). New York: Routledge.

Wenger, Etienne. 1998. Communities of practice: Learning, meaning, and identity. New York, NY: Cambridge university press.

Wenger, Etienne. 2009. A social theory of learning. In Contemporary theories of learning: Learning theorists-in their own words, edited by Knud Illeris, 209-18. New York, NY: Routledge.

Wright, Ruth. 2010. Democracy, social exclusion and music education: Possibilities for change. In Sociology and music dducation, edited by Ruth Wright, 263-82. Farnham: Ashgate.

Smith, Gareth Dylan, and Clare Hall. 2018. Introduction to the special issue: The International Symposium on the Sociology of Music Education, and the MayDay Group action ideals. Action, Criticism, and Theory for Music Education 17 (3): 1-11. doi:10.22176/act17.3.1 